\title{
Update on Intensive Neuromonitoring for Patients with Traumatic Brain Injury: A Review of the Literature and the Current Situation
}

\author{
Hiroyasu KoIzumi, ${ }^{1}$ Eiichi SueHIRO, ${ }^{1}$ Yuichi FujIYAMA, ${ }^{1}$ Kazutaka SugIMOTO, ${ }^{1}$ \\ Takao INOUE, ${ }^{1}$ and Michiyasu SUZUKI ${ }^{1}$
}

${ }^{1}$ Department of Neurosurgery, Yamaguchi University School of Medicine, Ube, Yamaguchi

\begin{abstract}
Intracranial pressure (ICP) measurements are fundamental in the present protocols for intensive care of patients during the acute stage of severe traumatic brain injury. However, the latest report of a large scale randomized clinical trial indicated no association of ICP monitoring with any significant improvement in neurological outcome in severely head injured patients. Aggressive treatment of patients with therapeutic hypothermia during the acute stage of traumatic brain injury also failed to show any significant beneficial effects on clinical outcome. This lack of significant results in clinical trials has limited the therapeutic strategies available for treatment of severe traumatic brain injury. However, combined application of different types of neuromonitoring, including ICP measurement, may have potential benefits for understanding the pathophysiology of damaged brains. The combination of monitoring techniques is expected to increase the precision of the data and aid in prevention of secondary brain damage, as well as assist in determining appropriate time periods for therapeutic interventions. In this study, we have characterized the techniques used to monitor patients during the acute severe traumatic brain injury stage, in order to establish the beneficial effects on outcome observed in clinical studies conducted in the past and to follow up any valuable clues that point to additional strategies for aggressive management of these patients.
\end{abstract}

Key words: traumatic brain injury, intracranial pressure, pressure reactivity index, cerebral oxygenation, regional cerebral blood flow

\section{Introduction}

Intensive neuromonitoring of patients with severe traumatic brain injury in clinical studies has enhanced the scientific knowledge concerning the pathophysiological conditions of this type of brain injury at the acute stage. Although elimination of the primary brain damage resulting from the mechanical stress of a traumatic injury is not currently possible, neuromonitoring during the acute stage is conducive to gaining control of the intracranial physiological environment and providing better management of traumatically injured patients at the acute stage. Neuromonitoring is therefore potentially a reasonable approach for avoiding the occurrence of secondary brain damage. The guidelines for the management of severe head injury formulated in developed countries have been continually updated. The recent version of the guideline used in Japan also advocates the importance of neuromonitoring for management

Received May 2, 2014; Accepted June 28, 2014 of severe traumatic brain injury. ${ }^{1)}$ In this context, intracranial pressure (ICP) monitoring is considered to be a fundamental ${ }^{2)}$ neuromonitoring procedure for management of severe traumatic brain injury during the acute stage.

The accumulation of scientific knowledge regarding ICP monitoring over the last decades has served as the foundation for the establishment of the guidelines presently in use for the management of severe traumatic brain injury. ${ }^{3-5)}$ Monitoring of jugular venous oxygen saturation $\left(\mathrm{SjvO}_{2}\right)$ is another conventional practice that serves as an extended approach for evaluation of cerebral oxygen metabolism. Other recently developed devices include intracerebral microdialysis probes and other catheters for measurement of partial pressure of brain tissue oxygen $\left(\mathrm{PbtO}_{2}\right)$ and regional cerebral blood flow (rCBF). These advanced devices offer extended monitoring options and provide valuable information that cannot be obtained from morphological images such as computed tomography (CT) and magnetic resonance imaging. However, monitoring using these technologies can sometimes be difficult. 
In some situations, the use of advanced technologies requires technical assistance as well as correct interpretation of the data. Therefore, in some cases, monitoring using only one of these advanced technologies creates the risk of misinterpreting the underlying pathophysiological conditions. Therefore, a combination of several of these technologies would be more likely to lead to a correct interpretation of the clinical conditions. Monitoring of data derived from different threshold values would allow the application of additional therapeutic interventions and enable experienced clinicians to better manage their patients.

Previous clinical studies on the effects of intensive neuromonitoring of patients with severe traumatic brain injury were expected to achieve breakthrough results; however, whether this type of monitoring results in any dramatic improvement in outcome in these patients remains controversial. ${ }^{6-10)}$ This study reviews the current situation of intensive neuromonitoring in patients with severe traumatic brain injury at the acute stage (Table 1), with the aim of consolidating the available knowledge obtained in past clinical studies in order to discuss the outlook for treatment strategies for these patients.

\section{ICP Monitoring}

A clinical study in 1977 reported that intracranial hypertension was significantly associated with poor neurological outcome of patients who had suffered severe traumatic brain injury. ${ }^{2)}$ Several subsequent clinical studies published since the late 1970s have suggested that aggressive control of intracranial hypertension would be expected to improve the neurological outcome of these patients. ${ }^{11-13)}$ Several multicenter clinical studies, including randomized clinical trials and retrospective data collection from huge quantities of trauma registry around 2000, have shown a significant correlation between ICP

Table 1 Neuromonitoring techniques during the acute stage of severe traumatic brain injury

\begin{tabular}{lc}
\hline Type of monitoring & Monitoring techniques \\
\hline Cerebrovascular circulation & $\mathrm{ICP}, \mathrm{rCBF}$ \\
Cerebrovascular autoregulation & $\mathrm{PRx}, \mathrm{Mx}, \mathrm{PAx}, \mathrm{ORx}$ \\
Cerebral oxygenation & $\mathrm{PbtO}_{2}, \mathrm{NIRS}$ \\
Cerebral metabolites & Microdialysis \\
\hline
\end{tabular}

ICP: intracranial pressure, Mx: mean flow index, NIRS: near infrared spectroscopy, ORx: brain tissue oxygen pressure reactivity index, $\mathrm{PAx}$ : pressure-amplitude index, $\mathrm{PbtO}_{2}$ : partial pressure of brain tissue oxygen, PRx: pressure reactivity index, rCBF: regional cerebral blood flow. monitoring during the acute stage of severe traumatic brain injury and improved survival rate of the patients. ${ }^{14-17)}$ The Brain Trauma Foundation in the United States incorporated indications for ICP monitoring into a guideline for the management of severe traumatic brain injury. ${ }^{3)}$ The formulation of guidelines for traumatic brain injury care in the United States led to compliance rates of $68 \%$ in Level 1 trauma centers; however, full compliance with these guidelines was only $16 \% .^{4)}$ A revision of the current guidelines now recommends enforcement of ICP monitoring during the acute stage of traumatic brain injury. ${ }^{5)} \mathrm{A}$ recent clinical study investigating the large scale prospective database including a population of 2,134 patients with severe traumatic brain injury ${ }^{6)}$ reported that a treatment targeting ICP control with placement of ICP sensor during the acute stage significantly lowered patient mortality. This study included 1,446 patients who were treated for intracranial hypertension: 1,202 patients had injuries that indicated the use of an ICP monitor, while the remaining 244 patients were treated without ICP monitoring. In contrast to these positive findings obtained from this large-scale prospective database analysis, the latest multicentric randomized clinical controlled trial (BEST TRIP study), which generated highly reliable evidence, indicated that a targeted treatment focused on maintaining the monitored ICP at $20 \mathrm{mmHg}$ or less during the acute stage of severe traumatic brain injury failed to show any significant difference in the mortality when compared to the treatment without ICP monitoring. ${ }^{7)}$ The patients in the control group were treated based on imaging and clinical examination. The six-month mortality was $39 \%$ in the ICP monitored group and $41 \%$ in the imaging clinical examination group $(P=0.60)$. The median length of stay in the intensive care unit (ICU) was 12 days in the ICP monitored group and 9 days in the imaging clinical examination group $(P=0.25)$. The director of the BEST TRIP study stated that their results did not support the superiority of treatment based on ICP monitoring over treatment guided by neurologic testing and CT imaging regarding patient mortality; however, their results also did not argue against the use of ICP monitoring since both groups underwent treatment to lower intracranial hypertension. The purpose of their study was to determine whether the guidelinebased protocol used in their study provided any significantly improved outcome.

In conclusion, the consensus based on the current evidence is that ICP monitoring is recommended for patients with severe traumatic brain injury, even though the benefits regarding improved outcome remain controversial. 


\section{Pressure Reactivity Index}

Optimizing cerebral perfusion pressure (CPP) remains essential for cerebral oxygenation. The therapeutic threshold of CPP to the target lies within the range of $50 \mathrm{mmHg}$ to $70 \mathrm{mmHg}{ }^{18)}$ However, during the acute stage of severe traumatic brain injury, optimal CPP varies with the pathological condition of each individual case. When cerebrovascular autoregulation is preserved, the elevation of CPP induces a reduction in the volume of the cerebrovascular beds, which maintains a consistent level of cerebral blood flow (CBF) and reduces ICP. In contrast, cases of severe traumatic brain injury with impaired cerebrovascular autoregulation showed elevation of ICP that is positively correlated with CPP elevation. ${ }^{19)}$ Identification of the optimal CPP to compensate for the impaired cerebrovascular autoregulation is therefore difficult and varies by degree in each individual.

The pressure reactivity index (PRx) has recently drawn attention as a useful indicator that allows assessment of the severity of cerebrovascular autoregulation. ${ }^{20-22)} \mathrm{PRx}$ is calculated as a moving correlation coefficient between averaged values of arterial blood pressure and ICP. Negative values of PRx from -1 to 0 reflect a negative correlation between mean arterial blood pressure (MABP) and ICP, meaning that an active vasomotor reactivity of cerebrovascular autoregulation exists. In contrast, positive values of PRx from 0 to +1 indicate a passive vasomotor reaction suggestive of an impaired cerebrovascular autoregulation. A clinical study of 82 patients with head injuries who had an average Glasgow Coma Scale (GCS) score of 6 reported a positive value of PRx that was significantly correlated with high ICP, low admission GCS score, and poor outcome at 6 months after head injury. ${ }^{20)}$ The results from another study targeted at 98 head injured patients stated that a PRx value above 0.2 was indicative of defective cerebrovascular autoregulation. ${ }^{21)}$ Another clinical study suggested that the pressure reactivity of cerebrovascular autoregulation can be used to determine the validity of ICP-oriented or CPPoriented therapy for the individual cases of severe traumatic brain injury. ${ }^{22)}$ In that study, pressure reactivity was calculated as the slope of a regression line fitted to the data points of the mean ICP and MABP for each hour of computer monitoring. Results of another study based on data from 131 patients with traumatic brain injury suggested that ICP-oriented treatment should be used in patients who showed a slope of their MABP/ICP regression line of at least 0.13 . A slope value for less than 0.13 was also considered an indication for hypertensive CPP therapy to produce a better patient outcome.
In addition, when the optimal CPP was defined as the CPP where PRx reaches its minimum value in an individual patient, ${ }^{23,24)}$ head injured patients treated with a mean CPP that was close to the optimal value were reported to have a favorable outcome, unlike those whose mean CPP was far from optimal. ${ }^{24)}$ The CPP value that allowed PRx to reach its lowest value produced a better outcome, consistent with the prevailing notion that a high value for PRx during the acute stage was associated with poor outcome in patients with severe traumatic brain injury.

Other techniques besides PRx have also been suggested for monitoring of cerebrovascular autoregulation. The mean flow index (Mx) is calculated as a moving correlation coefficient between spontaneous fluctuations of mean flow velocity and CPP. ${ }^{20,25,26)}$ In this approach, mean flow velocity of the middle cerebral artery is derived from transcranial Doppler flow measurements. Mx monitoring has been reported to be useful as an approach to assess CBF autoregulation. Studies that included patients with subarachnoid hemorrhage in addition to traumatic brain injury reported that the pulse amplitude of ICP (AMP) was a better marker of the patient's state and a better predictor of neurological outcome than were the mean values of ICP. ${ }^{27)}$

Elevated AMP is considered to indicate a brain metabolism crisis and subsequently increases the risk of mortality or severe disability at follow up. $^{28,29)}$ Another index, the pressure-amplitude index (PAx), calculated as the Pearson correlation between MABP and AMP, has shown a significant correlation between $\mathrm{Mx}$ and PAx in patients with severe traumatic brain injury at the acute stage. ${ }^{30}$ Further prospective studies are still required to evaluate the benefits of this autoregulation-oriented approach for these patients.

\section{Monitoring of Cerebral Oxygenation}

Cerebral hypoxia, attributed mainly to impaired autoregulation, systemic hypotension, and intracranial hypertension, has been identified as a principal cause of secondary brain damage following severe traumatic brain injury. ${ }^{31-35)}$ This secondary damage occurs even in some patients with severe traumatic brain injury who have controlled ICP and adequate CPP. Recent clinical studies have suggested that direct monitoring brain tissue $\mathrm{O}_{2}$ can detect brain hypoxia during the acute stage of severe traumatic brain injury. ${ }^{8,36-38)}$ At present, commercially available products are available for measuring the partial pressure of oxygen in brain tissue (brain tissue $\mathrm{PO}_{2}$ : $\mathrm{PbtO}_{2}$ ) in practical use. This approach was used 
in a clinical study that investigated a group of 25 patients with severe traumatic brain injury, where $29 \%$ of patients with ICP levels of $25 \mathrm{mmHg}$ or less and $27 \%$ of patients with CPP levels of $60 \mathrm{mmHg}$ or greater had severe cerebral hypoxia $\left(\mathrm{PbtO}_{2} \leqq 10\right.$ mmHg). In addition, even in $21 \%$ of the patients with optimal ICP $(<25 \mathrm{mmHg})$ and CPP (>60 $\mathrm{mmHg})$, severe cerebral hypoxia of $\mathrm{PbtO}_{2}$ less than $10 \mathrm{mmHg}$ was confirmed. ${ }^{36)}$ Poor neurological outcome was also associated with hypoxic $\mathrm{PbtO}_{2}$ values. ${ }^{37,38)}$

Monitoring of brain tissue oxygen coupled with the conventional ICP/CPP monitoring has been reported to improve the outcome of the patients with traumatic brain injury. ${ }^{8,9)}$ One clinical study showed a trend toward improved outcome in a group of 53 patients with severe traumatic brain injury treated with ICP/ CPP and $\mathrm{PbtO}_{2}$ monitoring when compared to another group of 40 patients treated with conventional ICP/ CPP monitoring. ${ }^{8)}$ A separate report indicated that the mortality rate was significantly reduced in patients with severe traumatic brain injury who underwent $\mathrm{PbtO}_{2}$-directed treatment, compared to patients who underwent ICP monitoring alone $(25 \%$ vs. $44 \%$, $P<0.05){ }^{99}$ However, a later report that included a relatively extensive analysis of retrospective data from 629 patients admitted to a Level I trauma center with a diagnosis of severe traumatic brain injury, concluded that clinical management guided by $\mathrm{PbtO}_{2}$ monitoring did not reduce the mortality rate when compared with ICP monitoring alone. ${ }^{10}$ The median length of hospital stay was also $27 \%$ longer in the $\mathrm{PbtO}_{2}$ monitored group than in the group that underwent ICP monitoring alone. The patients who underwent $\mathrm{ICP} / \mathrm{PbtO}_{2}$ monitoring were also younger in age and more severely injured, as determined by the admission GCS score and the head abbreviated injury scale (AIS) score, when compared to the patients treated with ICP monitoring alone. The authors of the study suggested that randomized clinical trials were needed to eliminate these demographic differences in order to verify the beneficial effects of direct brain tissue oxygen monitoring on the neurological outcomes of patients with severe traumatic brain injury.

As with the PRx, the correlation coefficient between $\mathrm{PbtO}_{2}$ and CPP has been advocated as an index of brain tissue oxygen pressure reactivity (ORx). The ORx has been considered to serve as an indicator of cerebral autoregulation after subarachnoid hemorrhage. ${ }^{39)}$ A clinical study investigating a group of patients after subarachnoid hemorrhage reported that the ORx indicated impaired autoregulation in patients who develop delayed infarction following cerebral vasospasms after subarachnoid hemorrhage.
The mean ORx value was significantly higher in the infarction group than in the noninfarction group. However, any beneficial effects of treatment guided by the ORx on clinical outcome of traumatic brain injury patients remain controversial at present. ${ }^{40-42)}$

Near infrared spectroscopy (NIRS) is an optical technique used to examine the oxygenation state of tissues such as the injured brain of patients. This technique continuously and non-invasively monitors the changes in oxygenation of brain tissue. Several studies have already shown the usefulness of NIRS for detecting cerebral ischemia in stroke patients. ${ }^{43-45}$ ) NIRS appears to be particularly useful for detecting the changes in cortical oxygen saturation due to vasospasm following subarachnoid hemorrhage. ${ }^{46-49)}$ However, insufficient clinical studies have been targeted thus far at patients with traumatic brain injury. ${ }^{50,51)}$ At present, the evidence obtained from clinical investigations is not sufficiently convincing to support the usefulness of NIRS in the management of patients with traumatic brain injury during the acute stage. Hence, NIRS still has not attained widely prevalent use in clinical settings.

\section{Microdialysis}

Excitatory amino acids, typified by glutamate and aspartate, have received strong interest because of their potential role as causative factors of neuronal damage. ${ }^{52)}$ Intracerebral microdialysis is a method for harvesting of endogenous substances from extracellular fluid and is presently considered to be a clinically useful method for neurometabolic monitoring. ${ }^{53,54)}$ This technique was initially introduced for clinical use in the brain in 1990. ${ }^{53)}$ A clinical study using microdialysis targeted at traumatically head injured patients reported in 1998 ${ }^{54)}$ showed that sustained high ICP and poor outcome were significantly correlated with high extracellular levels of excitatory amino acids. However, intracerebral microdialysis is a local monitoring technique similar to $\mathrm{PbtO}_{2}$ monitoring, and not a global method like ICP or $\mathrm{SjvO}_{2}$ monitoring. Clinical studies comparing the data between dialysate obtained from the catheters located at a region close to focal traumatic lesions and remote from the focal lesions have demonstrated that changes in lactate/pyruvate (L/P) ratio and levels of glutamate were deterministically dependent on the location of microdialysis probes. ${ }^{55,56)}$ In addition, another clinical study of 21 severe traumatic head injured patients reported that the $\mathrm{L} / \mathrm{P}$ ratio obtained from the dialysate collected at a pericontusional lesion was increased in parallel with CPP reduction, while no change 
in $\mathrm{L} / \mathrm{P}$ ratio was observed in the simultaneously harvested dialysate from a normal lesion. ${ }^{57)}$ This result may imply that intracerebral microdialysis monitoring could be potentially meaningless as the data obtained depend on the location of catheters. This issue is presumably one of the reasons why intracerebral microdialysis has not seen widespread practical use in the clinical setting.

\section{Monitoring of rCBF}

A study investigating patients with severe traumatic brain injury, monitored continuously with thermal diffusion probe, showed that rCBF monitoring was useful for hastening interventions aimed at restoring adequate tissue perfusion. ${ }^{58)}$ Recently advanced technologies available in Europe and in the United States have led to commercially availability of a thermodiffusion probe for measuring rCBF. The probe is placed intraparenchymally into the brain of patients, and makes it technically possible to measure the rCBF continuously at the bedside. ${ }^{59,60)}$ However, the number of cases recruited in studies that have used the rCBF measuring probe is low. Therefore, large clinical trials are needed for investigating the usefulness of the thermodiffusion probe for patients with severe traumatic brain injury.

\section{Conclusion}

In this review, we have documented the results of several different neuromonitoring techniques used during the acute stage in patients with severe traumatic brain injury. These techniques are basically able to record various parameters continuously in real time, at the bedside, and they also allow therapeutic interventions to be established by detecting changes in intracranial pathophysiology. In the past, a multitude of novel agents with potential have been applied to the treatment of patients to reduce secondary brain damage following head trauma. Nevertheless, all of these clinical trials have ended in anticlimax. The introduction of a revolutionary neuroprotective treatment is unlikely in the immediate future. However, an increase in the precision of understanding of the intracranial pathophysiology of patients that can be obtained with continuous monitoring at each moment should be conducive for a better outcome for these patients. Accurate diagnosis and mediation of therapeutic interventions will require the establishment of patient-specific thresholds for each parameter used in continuous neuromonitoring during the acute stage of traumatic brain injury. The hope is that these approaches will result in a significant improvement in neurological outcomes of patients with traumatic brain injury in the future.

\section{Conflicts of Interest Disclosure}

There is no COI to be disclosed.

\section{References}

1) Shigemori M, Abe T, Aruga T, Ogawa T, Okudera H, Ono J, Onuma T, Katayama Y, Kawai N, Kawamata T, Kohmura E, Sakaki T, Sakamoto T, Sasaki T, Sato A, Shiogai T, Shima K, Sugiura K, Takasato Y, Tokutomi T, Tomita H, Toyoda I, Nagao S, Nakamura H, Park YS, Matsumae M, Miki T, Miyake Y, Murai H, Murakami S, Yamaura A, Yamaki T, Yamada K, Yoshimine T; Guidelines Committee on the Management of Severe Head Injury, Japan Society of Neurotraumatology: Guidelines for the Management of Severe Head Injury, 2nd Edition guidelines from the Guidelines Committee on the Management of Severe Head Injury, the Japan Society of Neurotraumatology. Neurol Med Chir (Tokyo) 52: 1-30, 2012

2) Miller JD, Becker DP, Ward JD, Sullivan HG, Adams WE, Rosner MJ: Significance of intracranial hypertension in severe head injury. J Neurosurg 47: 503-516, 1977

3) Guidelines for the management of severe head injury. Brain Trauma Foundation, American Association of Neurological Surgeons, Joint Section on Neurotrauma and Critical Care. J Neurotrauma 13: 641-734, 1996

4) Hesdorffer DC, Ghajar J, Iacono L: Predictors of compliance with the evidence-based guidelines for traumatic brain injury care: a survey of United States trauma centers. J Trauma 52: 1202-1209, 2002

5) Brain Trauma Foundation; American Association of Neurological Surgeons; Congress of Neurological Surgeons; Joint Section on Neurotrauma and Critical Care, AANS/CNS, Bratton SL, Chestnut RM, Ghajar J, McConnell Hammond FF, Harris OA, Hartl R, Manley GT, Nemecek A, Newell DW, Rosenthal G, Schouten J, Shutter L, Timmons SD, Ullman JS, Videtta W, Wilberger JE, Wright DW: Guidelines for the management of severe traumatic brain injury. VI. Indications for intracranial pressure monitoring. J Neurotrauma 24(Suppl 1): S37-S44, 2007

6) Farahvar A, Gerber LM, Chiu YL, Carney N, Härtl R, Ghajar J: Increased mortality in patients with severe traumatic brain injury treated without intracranial pressure monitoring. J Neurosurg 117: 729-734, 2012

7) Chesnut RM, Temkin N, Carney N, Dikmen S, Rondina C, Videtta W, Petroni G, Lujan S, Pridgeon J, Barber J, Machamer J, Chaddock K, Celix JM, Cherner M, Hendrix T; Global Neurotrauma Research Group: A trial of intracranial-pressure monitoring in traumatic 
brain injury. N Engl J Med 367: 2471-2481, 2012

8) Meixensberger J, Jaeger M, Väth A, Dings J, Kunze E, Roosen K: Brain tissue oxygen guided treatment supplementing ICP/CPP therapy after traumatic brain injury. J Neurol Neurosurg Psychiatr 74: 760-764, 2003

9) Stiefel MF, Spiotta A, Gracias VH, Garuffe AM, Guillamondegui O, Maloney-Wilensky E, Bloom S, Grady MS, LeRoux PD: Reduced mortality rate in patients with severe traumatic brain injury treated with brain tissue oxygen monitoring. $J$ Neurosurg 103: 805-811, 2005

10) Martini RP, Deem $S$, Yanez ND, Chesnut RM, Weiss NS, Daniel S, Souter M, Treggiari MM: Management guided by brain tissue oxygen monitoring and outcome following severe traumatic brain injury. J Neurosurg 111: 644-649, 2009

11) Becker DP, Miller JD, Ward JD, Greenberg RP, Young HF, Sakalas R: The outcome from severe head injury with early diagnosis and intensive management. J Neurosurg 47: 491-502, 1977

12) Marshall LF, Smith RW, Shapiro HM: The outcome with aggressive treatment in severe head injuries. Part I: the significance of intracranial pressure monitoring. J Neurosurg 50: 20-25, 1979

13) Miller JD, Butterworth JF, Gudeman SK, Faulkner JE, Choi SC, Selhorst JB, Harbison JW, Lutz HA, Young HF, Becker DP: Further experience in the management of severe head injury. J Neurosurg 54: 289-299, 1981

14) Bulger EM, Nathens AB, Rivara FP, Moore M, MacKenzie EJ, Jurkovich GJ; Brain Trauma Foundation: Management of severe head injury: institutional variations in care and effect on outcome. Crit Care Med 30: 1870-1876, 2002

15) Juul N, Morris GF, Marshall SB, Marshall LF: Intracranial hypertension and cerebral perfusion pressure: influence on neurological deterioration and outcome in severe head injury. $J$ Neurosurg 92: 1-6, 2000

16) Lane PL, Skoretz TG, Doig G, Girotti MJ: Intracranial pressure monitoring and outcomes after traumatic brain injury. Can J Surg 43: 442-448, 2000

17) McKinley BA, Parmley CL, Tonneson AS: Standardized management of intracranial pressure: a preliminary clinical trial. J Trauma 46: 271-279, 1999

18) Brain Trauma Foundation; American Association of Neurological Surgeons; Congress of Neurological Surgeons; Joint Section on Neurotrauma and Critical Care, AANS/CNS, Bratton SL, Chestnut RM, Ghajar J, McConnell Hammond FF, Harris OA, Hartl R, Manley GT, Nemecek A, Newell DW, Rosenthal G, Schouten J, Shutter L, Timmons SD, Ullman JS, Videtta W, Wilberger JE, Wright DW: Guidelines for the management of severe traumatic brain injury. IX. Cerebral perfusion thresholds. J Neurotrauma 24(Suppl 1): S59-S64, 2007

19) Rosner MJ, Rosner SD, Johnson AH: Cerebral perfusion pressure: management protocol and clinical results. J Neurosurg 83: 949-962, 1995
20) Czosnyka M, Smielewski P, Kirkpatrick P, Laing RJ, Menon D, Pickard JD: Continuous assessment of the cerebral vasomotor reactivity in head injury. Neurosurgery 41: 11-17; discussion 17-19, 1997

21) Czosnyka M, Smielewski P, Kirkpatrick P, Piechnik S, Laing R, Pickard JD: Continuous monitoring of cerebrovascular pressure-reactivity in head injury. Acta Neurochir Suppl 71: 74-77, 1998

22) Howells $T$, Elf $K$, Jones PA, Ronne-Engström E, Piper I, Nilsson P, Andrews P, Enblad P: Pressure reactivity as a guide in the treatment of cerebral perfusion pressure in patients with brain trauma. J Neurosurg 102: 311-317, 2005

23) Depreitere B, Güiza F, Van den Berghe G, Schuhmann MU, Maier G, Piper I, Meyfroidt G: Pressure autoregulation monitoring and cerebral perfusion pressure target recommendation in patients with severe traumatic brain injury based on minute-by-minute monitoring data. J Neurosurg 120: 1451-1457, 2014

24) Steiner LA, Czosnyka M, Piechnik SK, Smielewski P, Chatfield D, Menon DK, Pickard JD: Continuous monitoring of cerebrovascular pressure reactivity allows determination of optimal cerebral perfusion pressure in patients with traumatic brain injury. Crit Care Med 30: 733-738, 2002

25) Czosnyka M, Smielewski P, Kirkpatrick P, Menon DK, Pickard JD: Monitoring of cerebral autoregulation in head-injured patients. Stroke 27: 1829-1834, 1996

26) Budohoski KP, Czosnyka M, de Riva N, Smielewski P, Pickard JD, Menon DK, Kirkpatrick PJ, Lavinio A: The relationship between cerebral blood flow autoregulation and cerebrovascular pressure reactivity after traumatic brain injury. Neurosurgery 71: 652-660; discussion 660-661, 2012

27) Bentsen G, Stubhaug A, Eide PK: Differential effects of osmotherapy on static and pulsatile intracranial pressure. Crit Care Med 36: 2414-2419, 2008

28) Eide PK, Brean A: Intracranial pulse pressure amplitude levels determined during preoperative assessment of subjects with possible idiopathic normal pressure hydrocephalus. Acta Neurochir (Wien) 148: 1151-1156; discussion 1156, 2006

29) Carrera E, Kim DJ, Castellani G, Zweifel C, Czosnyka Z, Kasprowicz M, Smielewski P, Pickard JD, Czosnyka M: What shapes pulse amplitude of intracranial pressure? J Neurotruma 27: 317-324, 2010

30) Radolovich DK, Aries MJ, Castellani G, Corona A, Lavinio A, Smielewski P, Pickard JD, Czosnyka M: Pulsatile intracranial pressure and cerebral autoregulation after traumatic brain injury. Neurocrit Care 15: 379-386, 2011

31) Gopinath SP, Robertson CS, Contant CF, Hayes C, Feldman Z, Narayan RK, Grossman RG: Jugular venous desaturation and outcome after head injury. J Neurol Neurosurg Psychiatr 57: 717-723, 1994

32) Chesnut RM, Marshall SB, Piek J, Blunt BA, Klauber MR, Marshall LF: Early and late systemic hypotension as a frequent and fundamental source of cerebral ischemia following severe brain injury 
in the Traumatic Coma Data Bank. Acta Neurochir Suppl (Wien) 59: 121-125, 1993

33) Marmarou A, Anderson RL, Ward JD, Choi SC, Young HF, Eisenberg HM, Foulkes MA, Marshall LF, Jane JA: Impact of ICP instability and hypotension on outcome in patients with severe head trauma. J Neurosurg 75: S59-S66, 1991

34) Bouma GJ, Muizelaar JP, Choi SC, Newlon PG, Young HF: Cerebral circulation and metabolism after severe traumatic brain injury: the elusive role of ischemia. J Neurosurg 75: 685-693, 1991

35) Cruz J: On-line monitoring of global cerebral hypoxia in acute brain injury. Relationship to intracranial hypertension. J Neurosurg 79: 228-233, 1993

36) Stiefel MF, Udoetuk JD, Spiotta AM, Gracias VH, Goldberg A, Maloney-Wilensky E, Bloom S, Le Roux PD: Conventional neurocritical care and cerebral oxygenation after traumatic brain injury. J Neurosurg 105: 568-575, 2006

37) Valadka AB, Gopinath SP, Contant CF, Uzura M, Robertson CS: Relationship of brain tissue $\mathrm{PO}_{2}$ to outcome after severe head injury. Crit Care Med 26: 1576-1581, 1998

38) van den Brink WA, van Santbrink H, Steyerberg EW, Avezaat CJ, Suazo JA, Hogesteeger C, Jansen WJ, Kloos LM, Vermeulen J, Maas AI: Brain oxygen tension in severe head injury. Neurosurgery 46 : 868-876; discussion 876-878, 2000

39) Jaeger M, Schuhmann MU, Soehle M, Nagel C, Meixensberger J: Continuous monitoring of cerebrovascular autoregulation after subarachnoid hemorrhage by brain tissue oxygen pressure reactivity and its relation to delayed cerebral infarction. Stroke 38: 981-986, 2007

40) Jaeger M, Schuhmann MU, Soehle M, Meixensberger J: Continuous assessment of cerebrovascular autoregulation after traumatic brain injury using brain tissue oxygen pressure reactivity. Crit Care Med 34: 1783-1788, 2006

41) Radolovich DK, Czosnyka M, Timofeev I, Lavinio A, Hutchinson P, Gupta A, Pickard JD, Smielewski $\mathrm{P}$ : Reactivity of brain tissue oxygen to change in cerebral perfusion pressure in head injured patients. Neurocrit Care 10: 274-279, 2009

42) Dengler J, Frenzel C, Vajkoczy P, Horn P, Wolf S: The oxygen reactivity index and its relation to sensor technology in patients with severe brain lesions. Neurocrit Care 19: 74-78, 2013

43) Liebert A, Wabnitz H, Steinbrink J, Möller M, Macdonald R, Rinneberg H, Villringer A, Obrig H: Bed-side assessment of cerebral perfusion in stroke patients based on optical monitoring of a dye bolus by time-resolved diffuse reflectance. Neuroimage 24: 426-435, 2005

44) Al-Rawi PG, Smielewski P, Kirkpatrick PJ: Evaluation of a near-infrared spectrometer (NIRO 300) for the detection of intracranial oxygenation changes in the adult head. Stroke 32: 2492-2500, 2001

45) Beese U, Langer H, Lang W, Dinkel M: Comparison of near-infrared spectroscopy and somatosensory evoked potentials for the detection of cerebral ischemia during carotid endarterectomy. Stroke 29: 2032-2037, 1998

46) Yokose N, Sakatani K, Murata Y, Awano T, Igarashi T, Nakamura S, Hoshino T, Katayama Y: Bedside monitoring of cerebral blood oxygenation and hemodynamics after aneurysmal subarachnoid hemorrhage by quantitative time-resolved near-infrared spectroscopy. World Neurosurg 73: 508-513, 2010

47) Mutoh T, Ishikawa T, Suzuki A, Yasui N: Continuous cardiac output and near-infrared spectroscopy monitoring to assist in management of symptomatic cerebral vasospasm after subarachnoid hemorrhage. Neurocrit Care 13: 331-338, 2010

48) Mutoh T, Kobayashi S, Tamakawa N, Ishikawa $\mathrm{T}$ : Multichannel near-infrared spectroscopy as a tool for assisting intra-arterial fasudil therapy for diffuse vasospasm after subarachnoid hemorrhage. Surg Neurol Int 2: 68, 2011

49) Maslehaty H, Krause-Titz U, Petridis AK, Barth H, Mehdorn HM: Continuous measurement of cerebral oxygenation with near-infrared spectroscopy after spontaneous subarachnoid hemorrhage. ISRN Neurol doi: 10.5402/2012/907187. Epub 2012

50) Tachtsidis I, Tisdall MM, Pritchard C, Leung TS, Ghosh A, Elwell CE, Smith M: Analysis of the changes in the oxidation of brain tissue cytochromec-oxidase in traumatic brain injury patients during hypercapnoea: a broadband NIRS study. Adv Exp Med Biol 701: 9-14, 2011

51) Kim MN, Durduran T, Frangos S, Edlow BL, Buckley EM, Moss HE, Zhou C, Yu G, Choe R, MaloneyWilensky E, Wolf RL, Grady MS, Greenberg JH, Levine JM, Yodh AG, Detre JA, Kofke WA: Noninvasive measurement of cerebral blood flow and blood oxygenation using near-infrared and diffuse correlation spectroscopies in critically brain-injured adults. Neruocrit Care 12: 173-180, 2010

52) Rothman SM, Olney JW: Excitotoxicity and NMDA receptor. Trends Neurosci 1: 299-302, 1987

53) Hillered L, Persson L, Pontén U, Ungerstedt U: Neurometabolic monitoring of the ischaemic human brain using microdialysis. Acta Neurochir (Wien) 102: 91-97, 1990

54) Bullock R, Zauner A, Woodward JJ, Myseros J, Choi SC, Ward JD, Marmarou A, Young HF: Factors affecting excitatory amino acid release following severe human head injury. J Neurosurg 89: 507-518, 1998

55) Engström M, Polito A, Reinstrup P, Romner B, Ryding E, Ungerstedt U, Nordström CH: Intracerebral microdialysis in severe brain trauma: the importance of catheter location. J Neurosurg 102: 460-469, 2005

56) Koizumi H, Fujisawa H, Nomura S, Kato S, Kajiwara K, Fujii M, Suzuki M: Dual microdialysis probe monitoring for patients with traumatic brain injury. Acta Neurochir Supple 102: 193-196, 2008

57) Vespa PM, O’Phelan K, McArthur D, Miller C, Eliseo M, Hirt D, Glenn T, Hovda DA: Pericontusional 
brain tissue exhibits persistent elevation of lactate/ pyruvate ratio independent of cerebral perfusion pressure. Crit Care Med 35: 1153-1160, 2007

58) Dickman CA, Carter LP, Baldwin HZ, Harrington T, Tallman D: Continuous regional cerebral blood flow monitoring in acute craniocerebral trauma. Neurosurgery 28: 467-472, 1991

59) Vajkoczy P, Roth H, Horn P, Lucke T, Thomé C, Hubner U, Martin GT, Zappletal C, Klar E, Schilling L, Schmiedek P: Continuous monitoring of regional cerebral blood flow: experimental and clinical validation of a novel thermal diffusion microprobe. $J$ Neurosurg 93: 265-274, 2000
60) Soukup J, Bramsiepe I, Brucke M, Sanchin L, Menzel M: Evaluation of a bedside monitor of regional CBF as a measure of $\mathrm{CO} 2$ reactivity in neurosurgical intensive care patients. J Neurosurg Anesthesiol 20: 249-255, 2008

Address reprint requests to: Hiroyasu Koizumi, MD, $\mathrm{PhD}$, Department of Neurosurgery, Yamaguchi University School of Medicine, 1-1-1 Minami-Kogushi, Ube, Yamaguchi 755-8505, Japan.

e-mail: hiroyasu@yamaguchi-u.ac.jp 